\title{
Relative geographic range of sibling species of host damselflies does not reliably predict differential parasitism by water mites
}

\author{
Julia J Mlynarek ${ }^{1 * \dagger}$, Wayne Knee ${ }^{2 \dagger}$ and Mark R Forbes ${ }^{1+}$
}

\begin{abstract}
Background: One of the main challenges in evolutionary parasitology is to determine the factors that explain variation among host species in parasitism. In this study, we addressed whether host phylogeny or ecology was important in determining host species use by water mites. Parasitism (prevalence and intensity) by Arrenurus water mites was examined in relation to geographic distribution of host damselflies from sibling species pairs. In addition, the likelihood of putative mite species parasitizing both species of a host species pair was explored.

Results: A total of 1162 damselflies were examined for water mites across four sites in Southeastern Ontario. These damselflies represent ten species (five closely related host species pairs) in the Coenagrionidae. Only two of the five species pairs showed near significant or significant differences in prevalence of infection by mites. In one of those species comparisons, it was the less widespread host that had higher water mite prevalence and in the other species comparison, the less widespread host species had lower water mite prevalence. Only one of the five pairs showed a significant difference in intensity of infection; intensity was higher in the species with a smaller geographic distribution. Based on the COI barcode, there were nine water mite clades (OTU) infecting these ten host species. Three Arrenurus OTUs may be host monospecific, four OTUs were specific to a given host species pair, and two OTUs infected at least three host species. Host species in each species pairs tend to share at least one of the Arrenurus OTU. No striking differences in mite species diversity were found among species in any species pair. Finally, the Arrenurus examined in this study appear to be ecological specialists, restricted to a particular type of habitat, parasitizing few to many of the host species present in that site or habitat.

Conclusions: Although differences in levels of parasitism by water mites exist for some closely related hosts species, no such differences were found between other related host species. Differences in geographic range of related host species does not reliably explain differential levels of parasitism by water mites.
\end{abstract}

\section{Background}

A major challenge of the combined fields of ecological and evolutionary parasitology is to understand the determinants of variation in parasitism between closely related host species [1,2]. Some of the proposed determinants include size of a host species' geographic distribution [3], host size [4], taxonomic relatedness of host species [5] and habitat requirements of both hosts and parasites [6,7]. Most of the research in this area has been done on vertebrate hosts

\footnotetext{
* Correspondence: julia_mlynarek@carleton.ca

${ }^{\dagger}$ Equal contributors

'Department of Biology, Carleton University, Nesbitt Building, 1125 Colonel By Drive, Ottawa, ON K1S 5B6, Canada

Full list of author information is available at the end of the article
}

(e.g., [8]). A question remains as to whether it is possible to extrapolate findings of studies on vertebrates and their parasites to similar problems with invertebrate host species and their parasites.

Some generalities can be drawn from studies on parasitism of vertebrates as a guide to explorations of parasitism of invertebrate hosts. For example, host species with a greater geographic range may come into contact with infective stages of more parasite species and therefore have higher diversity of parasites or higher parasitism levels $[9,10]$. Alternatively, hosts with larger geographic areas might evolve more generalized immune responses and therefore have fewer parasites in local areas (cf. [11]). Using damselflies and gregarines, Mlynarek et al. [11] 
demonstrated that in three out of seven species pairs, one host species had a statistically higher prevalence of gregarines, when controlling for collecting site. In two of those species comparisons, the sibling species with the smaller geographic distribution had higher prevalence; in the latter comparison, the species with the larger geographic distribution had the higher prevalence. Similarly, in two out of seven species pairs, the species that had a smaller geographic distribution had a statistically higher gregarine intensity [11].

Other studies with vertebrates and their parasites have demonstrated that host geographic distribution size can be related to parasite species richness $[3,4,12]$. The recurrent relation between host geographical range and parasite species diversity has been explained in part by increased chance of intense localized encounters between interacting species with the increasing range size of the host species $[10,13]$. Although host species with larger geographic distributions are expected to have more parasite species than closely related host species with smaller geographic ranges [10], it is unknown whether such patterns are observed often at given sites. Species with larger geographical ranges typically occupy more sites and might be subjected to more studies: a potential problem recognized early [12].

Several studies have looked at relationships between host and/or habitat characteristics and parasitism levels in insect host-invertebrate parasite associations. Durrer and Schmid-Hempel [14] studied regional and local abundance of bumblebees with respect to external and internal parasite load and diversity. Those researchers found that there was a positive correlation with parasite load and colony size, and also that parasite diversity correlated positively with regional distribution of hosts, but host body size did not affect any of the measures. Jaenike and Perlman [15] reviewed the role of nematode parasites on mycophagous Drosophila behaviour, reproduction and community structure. Their work demonstrated that parasitism facilitates co-existence between closely related hosts and reduces fertility in female Drosophila. One other study compares parasitism levels explicitly between species differing in geographical representation, but there the focus is on gregarine parasites of calopterygid damselflies in allopatric versus sympatric associations [16].

For various reasons, the extent to which parasitism and parasite diversity varies as a function of geographic range can be explored effectively using coenagrionid damselflies and Arrenurus water mites. First, there is interspecific variation in ecological and evolutionary traits in closely related damselfly host species (e.g., host geographical distribution, local abundance, see [17]). Second, it is known that there are several generalist species among mites [18]. Third, Arrenurus infection has been demonstrated to vary between closely related lestid host species in different habitats [19] and between more distantly related host species in the same habitat [20]. Fourth, Arrenurus water mites first parasitize teneral adults and are easily recognized as unengorged but live, unengorged and resisted, and engorged external parasites. Importantly, these mites remain on one host for the duration of their parasitic life stage [21]. Larval Arrenurus embed their mouthparts into the teneral cuticle of their host and secrete a stylostome or feeding tube. Mites remain usually on the ventral side of the thorax, between the legs, or the last abdominal segments [21]. Once the host returns to a water body to mate and/or lay eggs, the water mite detaches and falls into the water to continue its life cycle. Different species of water mite are also known to inhabit different types of water bodies [21], setting the stage for particular associations to be habitat specific.

The objectives of this study were several-fold. First, we tested whether closely-related host species were differentially infected by water mites. We then determined if the relative size of geographical distribution of sibling host species was associated with relative parasitism levels and moreover whether the occasional patterns observed between gregarines and damselflies documented in Mlynarek et al. [11] was also observed when considering ectoparasitic mites. More specifically, we were testing whether host species with smaller geographic distribution have higher levels of ectoparasitism, by analogy. We then assessed whether closely-related host species were infected by the same putative Arrenurus species using molecular techniques for parasite identification thereby making comparisons of parasitism between sibling host species more direct. Related to this objective, we were interested in whether the host species with higher measures of parasitism were also those with greater numbers of parasite species. In addressing these objectives, we also examined the extent to which Arrenurus water mite species show habitat or host species preferences. In summary, we were interested in whether a host species geographical distribution influenced measures of ectoparasitism and whether the patterns were repeatable or potentially affected by moderator variables (host species identity, habitat used).

\section{Results}

\section{Measures of general Arrenurus parasitism}

In total, 1162 damselflies were collected across four sites in Southeastern Ontario, within a $20-\mathrm{km}$ radius of the Queen's University Biological Station (Table 1).

Prevalence of Arrenurus varied considerably between host species and species pairs (Table 1). Overall prevalence varied between 4\% in Argia moesta and 54\% in Enallagma vesperum. Both of those species were collected from Lake Opinicon. Significant or near significant differences in prevalence between species in sibling species pairs were 
Table 1 Details of parasitism in ten species of damselflies sampled at four sites

\begin{tabular}{|c|c|c|c|c|c|c|}
\hline Host species & Location & $\mathrm{N}$ (N infected) & Geographic range $\left(10^{6} \mathrm{Km}^{2}\right)$ & Mite OTU & Prevalence $(95 \% \mathrm{Cl})$ & Intensity $(95 \% \mathrm{Cl})$ \\
\hline Argia moesta & Lake Opinicon & $90(4)$ & 4.10 & 1,7 & $0.04(0.01-0.11)$ & $1.50(1-1.75)$ \\
\hline A. violaceae & Lake Opinicon & $97(8)$ & 3.98 & 1,9 & $0.08(0.04-0.16)$ & $5.75(1.38-18.13)$ \\
\hline Enallagma boreale & Barb Marsh & $57(15)$ & 6.53 & 4,5 & $0.26(0.16-0.39)$ & $4.60(2.86-7.36)$ \\
\hline E. ebrium & Barb Marsh & $106(31)$ & 4.35 & 4,5 & $0.29(0.21-0.39)$ & 10.16 (6.81-13.68) \\
\hline E. signatum & Lake Opinicon & $120(32)$ & 3.23 & 1,2 & $0.27(0.19-0.36)$ & $9.81(5.16-22.09)$ \\
\hline E. vesperum & Lake Opinicon & $101(54)$ & 2.6 & 1 & $0.54(0.43-0.63)$ & 11.35 (7.00-18.87) \\
\hline Ischnura posita & Osprey Marsh & $77(4)$ & 3.13 & $3,4,6$ & $0.05(0.01-0.13)$ & $3.25(1.00-5.50)$ \\
\hline I.verticalis & Osprey Marsh & $23(4)$ & 4.36 & $1,3,6$ & $0.17(0.05-0.39)$ & $6.75(1.50-16.50)$ \\
\hline Nehalennia gracilis & Hebert Bog & $208(25)$ & 1.51 & 8 & $0.12(0.08-0.17)$ & $2.12(1.60-3.44)$ \\
\hline N. irene & Hebert Bog & $284(45)$ & 4.03 & 8 & $0.16(0.12-0.21)$ & $1.78(1.42-2.76)$ \\
\hline
\end{tabular}

$\mathrm{N}$ represents the number of individuals of each species sampled. Geographic range of the host is provided. Confidence limits for prevalence and intensity are shown respectively.

found in two of five comparisons. In particular, there was a significant difference in prevalence between the species of Enallagma (Chromatallagma) $\left(\mathrm{x}^{2}=16.57 \mathrm{df}=1 \mathrm{p}<0.001\right)$ where $54 \%$ of Enallagma vesperum individuals were infected compared to $27 \%$ of E. signatum. Ischnura posita had a prevalence of $5 \%$ whereas I. verticalis had a prevalence of $17 \%$. The difference in prevalence in this species pair was close to significant $\left(x^{2}=3.58 \mathrm{df}=1 \mathrm{p}=0.06\right.$; Figure 1$)$. In comparison, no significant differences in prevalence were found for Argia, Enallagma subgenus Enallagma and Nehalennia (Table 2).

The data on mean intensity of infection told a similar story. Overall, the minimum mean intensity was 1.5 in A. moesta and the maximum was 11.9 in Enallagma ebrium (Table 1). In Enallagma (Enallagma), Enallagma boreale was infected by an average of 4.6 mites per infected host individual, but E. ebrium was infected by an average of 10.2 mites per individual $(\mathrm{t}=-2.65$ bootstrap $\mathrm{p}=0.01$; Figure 2). In Argia, Enallagma (Chromatallagma), Ischnura and Nehalennia no significant differences in intensity were found between the species (Table 2).

At least two species pairs showed no differences in either prevalence or mean intensity of infection and yet sibling species differed in geographical distribution (Argia and Nehalennia). The other three species pairs had a significant or near significant difference in prevalence or a significant difference in intensity. In Enallagma (Chromatallagma), $E$. vesperum had significantly higher prevalence of parasitism: this species has the smaller geographic distribution of the pair $\left(2.60 \times 10^{6} \mathrm{~km}^{2}\right.$ compared to $3.26 \times 10^{6} \mathrm{~km}^{2}$ in

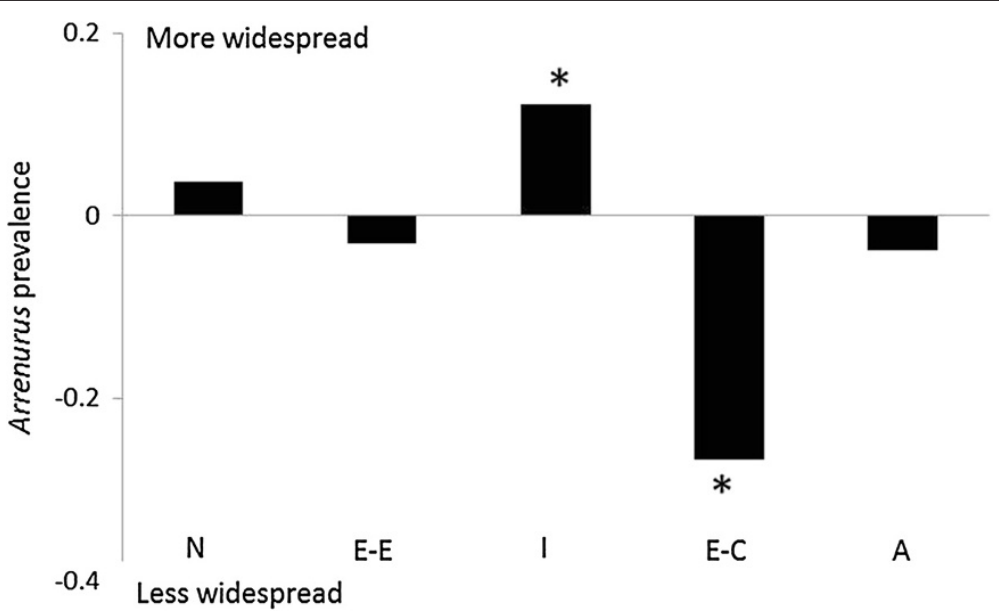

Figure 1 Within species pair difference in measures of prevalence between species. A positive difference means that the more widespread species of the species pair has higher estimate of prevalence of infection (from Table 1); a negative difference means that the less widespread species has higher estimate of prevalence. Actual significant differences in prevalence values are marked by *. The organization of the species pairs reflects geographical distribution differences within the species pair from most different to least different. Key: A, Argia; C, Calopteryx; E-C, Enallagma Chromatallagma; E-E, Enallagma Enallagma; I, Ischnura; N, Nehalennia. 
Table 2 Results of the Chi-square test for comparing prevalence and Bootstrap t-test for mean intensity of parasitic infection within the five Zygoptera species pairs

\begin{tabular}{lcccccc}
\hline Host species pair & \multicolumn{3}{c}{ Prevalence } & & \multicolumn{2}{c}{ Intensity } \\
\cline { 2 - 4 } & $\mathbf{X}^{\mathbf{2}}$ & $\mathbf{d f}$ & $\mathbf{p}$ & & t-value & Bootstrap $\mathbf{~}$ \\
\hline Argia & 1.12 & 1 & 0.29 & & 1.05 & 0.41 \\
Enallagma $E$ & 0.16 & 1 & 0.69 & & 2.65 & $\mathbf{0 . 0 1}$ \\
Enallagma $C$ & 16.57 & 1 & $<\mathbf{0 . 0 1}$ & & 0.33 & 0.35 \\
Ischnura & 3.58 & 1 & $\mathbf{0 . 0 6}$ & & 0.66 & 0.54 \\
Nehalennia & 1.44 & 1 & 0.52 & & 0.70 & 0.51 \\
\hline
\end{tabular}

E. signatum; Table 1). Similarly, in Enallagma (Enallagma), E. ebrium had significantly higher intensity of parasitism; E. ebrium is less widely distributed $\left(4.35 \times 10^{6} \mathrm{~km}^{2}\right)$ than E. boreale $\left(6.53 \times 10^{6} \mathrm{~km}^{2}\right.$; Table 1$)$. In Ischnura, I. verticalis has both nearly significant higher prevalence of water mite infection and larger geographic distribution than I. posita $\left(4.36 \times 10^{6} \mathrm{~km}^{2}\right.$ compared to $3.13 \times 10^{6} \mathrm{~km}^{2}$; Table 1). Thus in $60 \%$ of cases, sibling host species with differences in size of geographic distribution differed in either prevalence or intensity of parasitism, but in those cases the actual differences are inconsistently related to relative size of the pair member's geographic distribution.

\section{DNA barcoding}

COI was amplified from 62 water mites, with 587 characters in total, 296 constant, 50 parsimony-uninformative and 241 parsimony-informative. Mean base pair frequencies (A: 0.31574, C: 0.21282, G: 0.13819, T: 0.33325) were found to be homogenous across all specimens $\left(X^{2}=52.66\right.$, $\mathrm{df}=207 P=1.0)$.
Bayesian inference (BI) of the COI dataset was performed for 10 million generations, producing 19802 trees (after burn-in), which were summarized in a majority rule consensus tree $(\mathrm{TL}=1048, \mathrm{CI}=0.4599, \mathrm{RI}=0.8617)$ (Figure 3). The BI consensus tree was well supported, with most nodes having moderate to high posterior probabilities and jackknife support (Figure 3). The ingroup are divided into nine well-supported clades, hereafter referred to as OTU (Operational Taxonomic Units). Average interspecies divergence was $15 \% \pm 1.1(5-21 \%)$, and average intraspecies divergence was $0.7 \% \pm 0.3(0-4 \%)$. Average divergence between OTU 1, 2 and 3 was $9 \% \pm 1$, divergence between OTU 4 and 5 was $6 \% \pm 0.3$, between 6 and 7 was $10 \% \pm 0.3$, and species 8 and 9 show $8 \% \pm 0.3$ divergence. Considering the high level of divergence between OTU and the low divergence within each OTU, as well as the strong support for each OTU in the phylogenetic reconstruction, it appears that each OTU may be distinct. However, we do not advocate the notion that these are new species, distinguishing between species using pairwise distances from a fragment of a single gene is not a reliable taxonomic approach [22].

Based on our Bayesian tree (Figure 3), we found in Argia that there are three Arrenurus OTUs that infect Argia moesta and $A$. violaceae. OTU 9 is specific to $A$. violaceae and OTU 7 to $A$. moesta (Figure 3 ). Each of these OTUs is associated with a single host species, therefore we consider them to be candidates for specialist parasites. OTU 1 was collected both $A$. moesta and $A$. violaceae, and also two other Enallagma species (E. signatum and $E$. vesperum) from lake Opinicon indicating that this mite has a broad host species spectra (Figure 4). In addition, there is one record of this mite OTU present on Ischnura

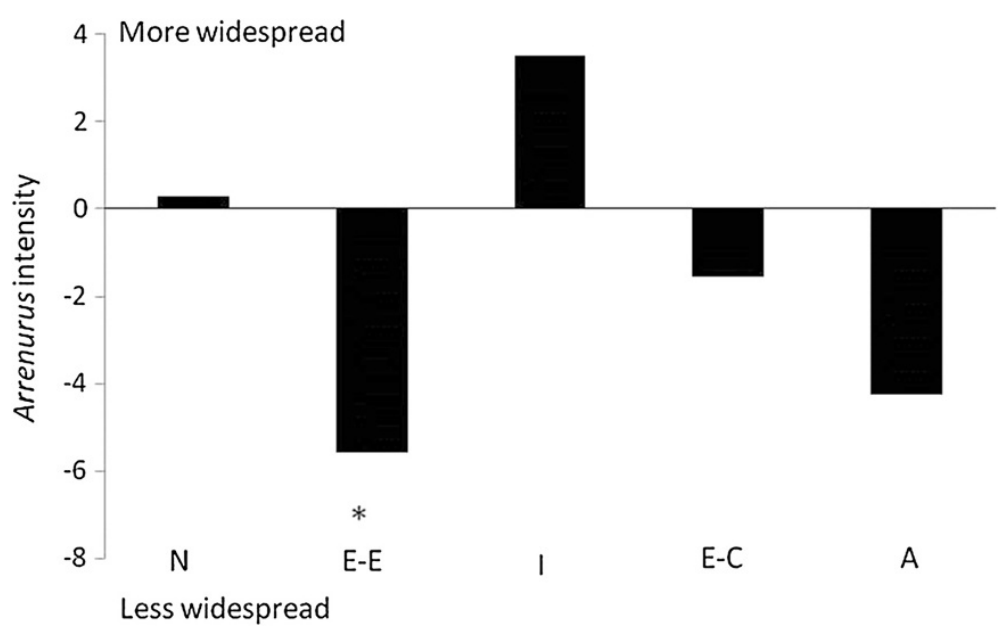

Figure 2 Within species pair difference in measures of intensity between species. A positive difference means that the more widespread species of the species pair has higher estimate of intensity of infection (from Table 1); a negative difference means that the less widespread species has higher estimate of intensity. Actual significant differences in prevalence values are marked by *. The organization of the species pairs as in Figure 1. 


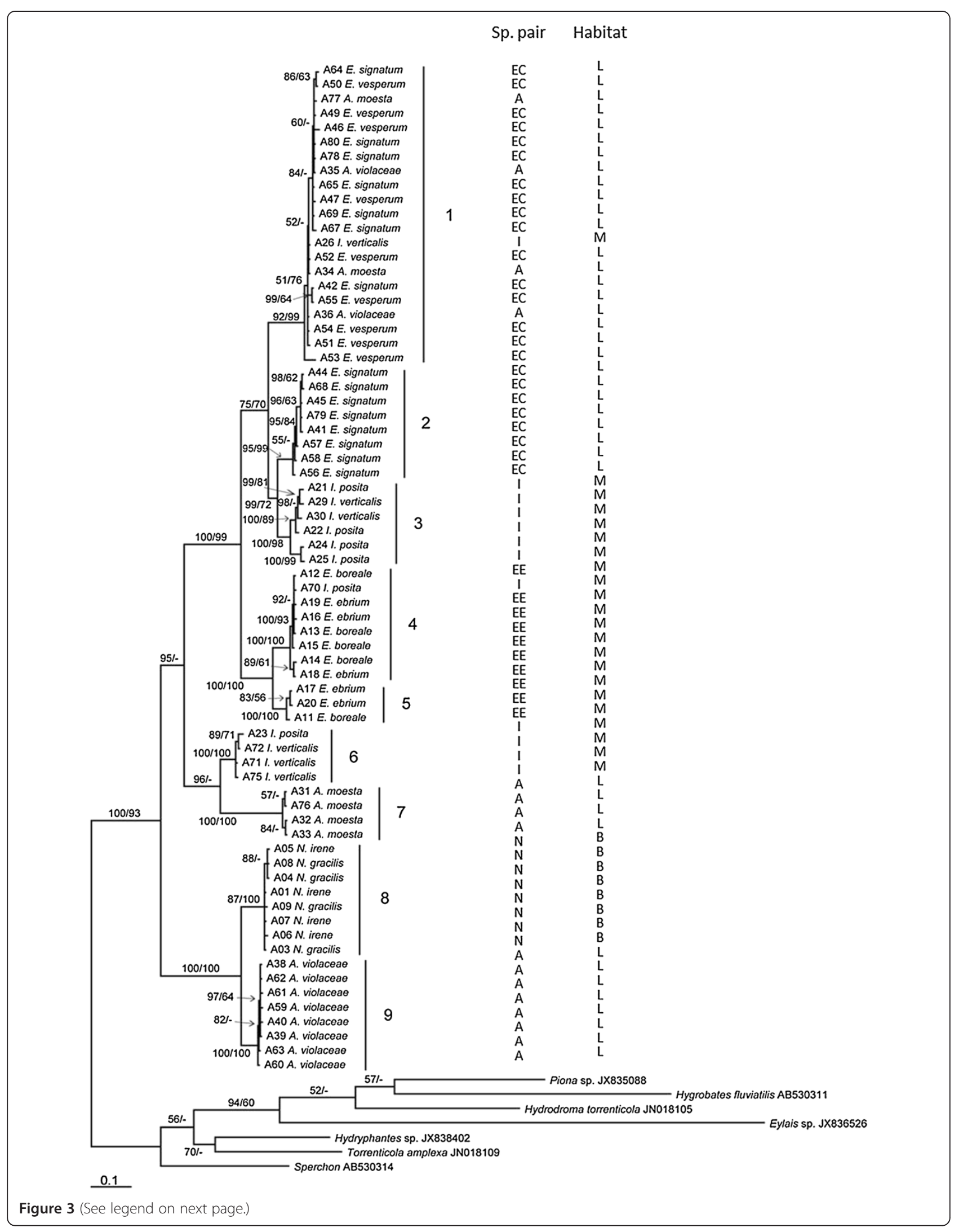


(See figure on previous page.)

Figure 3 Majority rule consensus tree of 19802 trees generated by Bayesian MCMC analysis (10 million generations) of 587 bp fragment of $\mathrm{COI}$ from 77 water mites, 70 ingroup and 7 outgroup specimens $(\mathrm{TL}=1048, \mathrm{Cl}=0.4599, \mathrm{RI}=0.8617)$ posterior probability $>\mathbf{5 0} \%$ / jackknife support. Species pair $\mathrm{A}=$ Argia; $\mathrm{EE}=$ Enallagma (Enallagma); $\mathrm{EC}=$ Enallagma (Chromatallagma); I=Ischnura; $\mathrm{N}=$ Nehalennia, habitat type $\mathrm{B}=$ Bog; $\mathrm{L}=$ Lake, $\mathrm{M}=$ Marsh.

verticalis in a marsh habitat. Interestingly, this broad host generalist was the only OTU collected from $E$. vesperum (out of 5 mites sampled). Thus, we discovered that mites of two host species pairs (examined first) shared a mite species (Figure 3).

Similarly, the two Enallagma (Enallagma) host species were both infected by two closely related OTUs (4 \& 5). These OTUs are distinct, based on sequence divergence and branch support, but are closely related to one another (Figure 3). Therefore these two OTUs were collected from at least these two species of damselflies. However, we could not determine whether these two parasite species were present on other host species. Again, it appears that sibling species share mite species. Ischnura is an interesting species pair in that four different OTUs have been collected from these hosts, despite the limited sampling. OTU 3 and 6 were collected from both Ischnura species again supporting sharing of parasites. But OTU 1, the aforementioned generalist on damselfly host species in the lake, was found on one Ischnura verticalis individual from a marsh inlet site. Additionally, OTU 4 (Figure 3) infecting I. posita is shared with Enallagma (Enallagma) damselfly hosts from a different marsh. Finally,

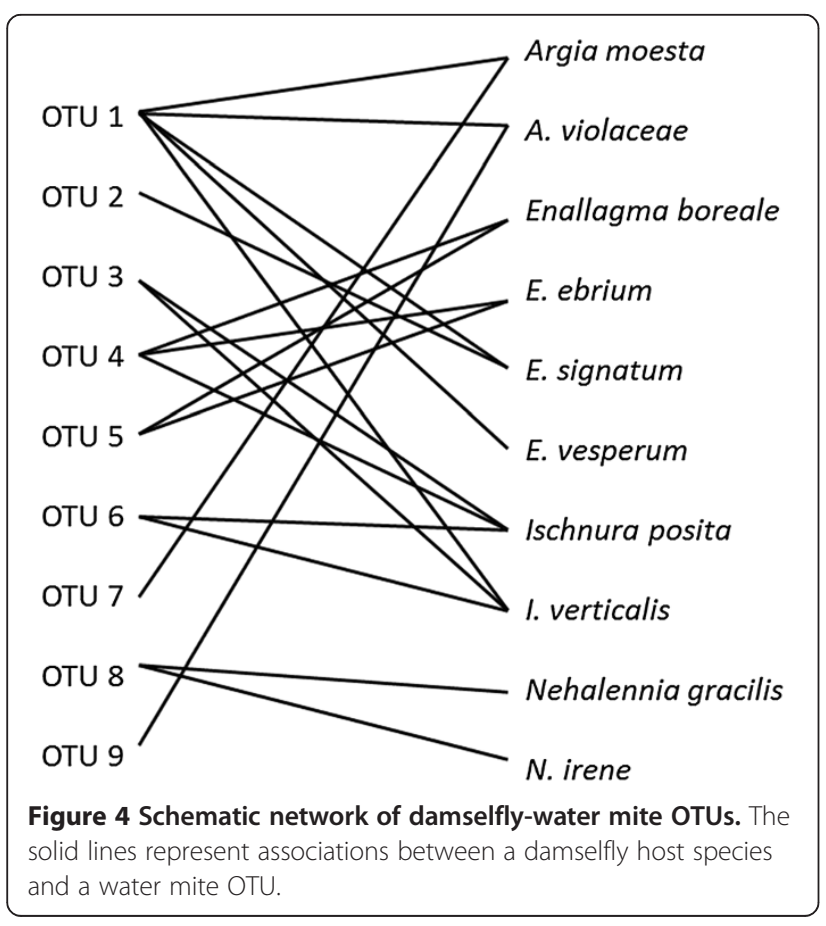

both Nehalennia species collected in the bog are infected by OTU 8 [17]. The results show that the sharing of mite species by sibling species of damselflies (and beyond those host clades) is a common occurrence (Figure 4). Species richness and composition within the host species pair did not differ (range of Bray-Curtis dissimilarity Index varied between 0.00 in Nehalennia to 0.86 in Argia) as much as between species pairs where the Bray-Curtis dissimilarity index ranged between $0.79-1.00$. The dissimilarity index on 0.79 was determined between $A$. violaceae and $E$. vesperum, which share water mite OTUs (Figure 4). Figure 3 is also annotated with whether or not the host and mites were collected from a lake, marsh or bog. It appears that mite species are restricted to one type of habitat but this is not a "hard and fast" rule.

\section{Discussion}

Relative geographic distribution size did predict relative prevalence of parasitism in some species pairs, but not reliably across all species pairs. To reiterate, there were significant differences in prevalence for Enallagma (Chromatallagma) species pair where the less widespread species had a higher prevalence of Arrenurus spp. In one instance (Ischnura species pair) did the more widespread host species, I. verticalis, have significantly higher intensity of Arrenurus than the more geographically restricted host species $I$. posita. Even referring to these two comparisons, geographic distribution is not a reliable predictor of parasitism in these types of insect host-invertebrate parasite associations. Across all other species pairs, differences in geographic distribution were evident, but no species differences is relative prevalence of ectoparasitism was observed. And furthermore, in only in the Enallagma (Enallagma) species pair, did the less widespread species have a higher mean intensity of infection by Arrenurus than the more widespread Enallagma species. Across all other species pairs, there were no species differences in mean intensity of mite parasitism.

In comparison to the findings in this study, Tella et al. [9] tested other factors that could potentially mask the effect of host geographic distribution such as sampling effort, vector availability and embryonic development time, but the researchers concluded that hematozoan prevalence appears determined by host geographic distribution. Mlynarek et al. [11] also reported that measures of gregarine parasitism were higher in the less widespread species pair in four out of the seven damselfly species pairs. Additional comparisons 
with this study demonstrate that the species pairs respond differently, depending on the type of parasite studied. For example, in Mlynarek et al. [11] Ischnura posita had a significantly higher prevalence of gregarines than its more widespread counterpart, Ischnura verticalis. In this study, Ischnura verticalis has a near significant higher prevalence of Arrenurus water mites than I. posita. Relative size of a host's geographic distribution, therefore, can have different or no effect on relative parasitism, depending on the type of parasite studied.

Based further on Mlynarek et al. [11] and this study, 12 species comparisons were done with respect to prevalence or intensity of either gregarines or mites. In half of the 12 species pair comparisons, there were statistical differences between species in either or both prevalence and intensity of either gregarine or mite infections. In four of these cases, the less widespread host species had higher prevalence and/or intensity of the parasite of interest whereas in the two remaining cases, it was the more widely distributed host with the higher parasite levels (prevalence of gregarines for Nehalennia and prevalence of mites for Ischnura). In one case, Enallagma (Chromatallagma), there were significant differences in both prevalence of mites and prevalence of gregarines whereby the less widespread host had higher prevalence of parasites. Stated another way, in four (57\%) of the seven comparisons involving gregarines and in three $(60 \%)$ of the five comparisons involving mites, closely related host species differed in one or more measures of parasitism. In the remaining $40 \%$ of the cases, the closely related species did not differ in measures of parasitism despite showing differences in geographical range. Further, in one (25\%) of four comparisons involving significant differences in gregarines, it was the more widely distributed host that had higher gregarine prevalence. A similar result was found where one $(33 \%)$ of three comparisons (Ischnura) involving significant differences in mite intensities, was attributed to the species with the greater geographic range.

In this study, using COI barcodes, there are nine OTUs within Arrenurus infecting the ten damselfly species. Arrenurus OTU 2, 7 and 9 appear specialized on a specific damselfly host species (E. signatum, A. moesta and $A$. violaceae), but sampling was limited. OTU 1 infects four host species in lakes. The Arrenurus OTUs 3,4,5,6 and 8, collected in the Marsh and bog, infect at least two species each. Water mites appear affiliated with a habitat and not so much specialized on phylogenetically related host species. Similarly to Krasnov et al. [7], habitat was a strong factor influencing flea parasitism on rodents in the Negev desert. As well, in our case and that of Krasnov et al. [5], both host species' and habitat characteristics are important in determining parasite species composition. Except for OTU 1, collected from an I. verticalis host, all the water mites are restricted to one particular habitat type. A potential reason could be that this $I$. verticalis individual was a vagrant into the marsh where it was collected, or that this mite is found in many habitats, mostly in lakes and rarely in others. The important point is that comparisons of parasitism between sibling species based on broad taxonomic identification of the parasites is somewhat permitted because all sibling host species share at least one mite species. If there was some strong interaction between a host geographic range and the intensity of interactions with given parasite species, it should be detected using even broad taxonomic comparisons, where only mites are being compared and not every parasite is identified to species.

There is a different pattern when comparing a group of parasites without considering broad taxonomic identification. When considering parasite species richness, it is expected that the more widespread hosts have a higher richness of parasite species [3]. In cricetid rodents, host geographic distribution was strongly associated with Demodex mite species richness [3]. In waterfowl, Gregory [12] demonstrated a clear positive relationship between host geographic range and parasite species richness, using cross-species comparisons. In European fresh-water fish, Simková et al. [4] concluded that host geographic distribution influenced parasite species richness through its effect on host local abundance and occurrence. Their research was based on 39 fish host species and a comprehensive assessment of internal and external parasites. In our case, we did not see this occurring but only can report on nine mite species across five pairs of damselfly host species. Notwithstanding, host species in each pair have a comparable number of mite species infesting them, even though certain host species might have species-specific parasites. The only exception in our study was Enallagma (Chromatallagma) species pair where the more widespread $E$. signatum has two Arrenurus OTUs (one host specific) whereas $E$. vesperum, the more restricted species, is only infected by one Arrenurus OTU. Even here, the conclusion that one host species has a higher parasite species diversity has to be met with scepticism, especially given that, when controlling for site, only one out of six instances does the more widespread species show this tendency toward higher parasite species richness.

\section{Conclusions}

In this study, we documented host- parasite associations in multiple species pairs. We observed that there appear to be varying degrees of specificity in host range of Arrenurus mites. In conjunction with the findings of Mlynarek et al. [11] on internal parasites of damselflies, our findings suggest that host species' geographic distribution size does not reliably explain relative species differences in measures of parasitism. Water mites species found in 
one type of habitat tend not to be present in another type of habitat but can parasitize few to many host species found in a habitat. More work is needed to further elucidate Arrenurus species boundaries, using additional molecular markers or rearing larvae for adult identification. Further work is needed on determining host species use before we can test the importance of other ecological factors (e.g. phenology or regional representation of both hosts and parasites) on past and ongoing evolution of these associations.

\section{Methods}

\section{Specimen collection}

Ten species of Coenagrionidae (Argia moesta and A. violaceae; Enallagma boreale and E. ebrium; E. signatum and E. vesperum; Ischnura posita and I. verticalis; and, Nehalennia gracilis and $N$. irene) were collected belonging to five sibling species pairs in Coenagrionidae based on (sub)generic affiliations (Argia, Enallagma (Enallagma), Enallagma (Chromatallagma) subgenus, Ischnura and Nehalennia). We considered the two Enallagma species pairs as separate because they are considered to be in separate subgenera [23]. The particular host species were chosen because a second closely related host species was found in sympatry and because species in sibling species pairs differed in geographic distribution size (minimum of $100000 \mathrm{~km}^{2}$ difference between the two species in each pair, see [11]).

We collected adult damselflies using aerial sweep nets between 17 May and 15 July 2010 and 30 May and 15 July 2011. Damselflies in each species pair were collected from the same site at the same time (see below). The damselflies were stored in separate vials with $95 \%$ ethanol.

Species pairs were collected at different sites and times because host emergence varies temporally and spatially. Argia moesta and A. violaceae and E. (Chromatallagma) signatum and $E$. (Chromatallagma) vesperum were collected at the edge of Lake Opinicon $\left(44^{\circ} 33^{\prime} 56.32^{\prime \prime} \mathrm{N}\right.$, $\left.76^{\circ} 19^{\prime} 26.46^{\prime \prime} \mathrm{W}\right)$ on 30 June to 10 July 2010; the species E. (Enallagma) boreale and E. (Enallagma) ebrium were collected at Barb's Marsh (44.31'27.54”N, 76 22'25.89”W) on 25 May, from 7 to 10 June 2010 and from 31 May to 21 June 2011, I. posita and I. verticalis were collected at a slow stream by Osprey Marsh (44.30'43.74”N, $\left.76^{\circ} 23^{\prime} 39.32^{\prime \prime W}\right)$ on 4 and 10 July 2010, N. gracilis and N. irene were collected at Hebert Bog $\left(44^{\circ} 29^{\prime} 54.69^{\prime \prime} \mathrm{N}, 76^{\circ} 24^{\prime} 53.66^{\prime \prime} \mathrm{W}\right)$ on 7 and 30 June 2011 and from 6 June to 18 July 2011.

All individuals collected were inspected for parasitism by looking at ventral side of the thorax and abdomen. All Arrenurus spp. water mites were counted.

\section{Statistical measures of general parasitism}

Differences between sibling species in prevalence, the proportion of hosts infected with at least one larval Arrenurus, and intensity, the mean number of Arrenurus on only the infected hosts, was assessed in QP3.0 [24]. Prevalence estimates were provided with Clopper-Pearson 95\% confidence intervals [25] whereas mean intensity estimates were provided with bootstrap confidence limits [24].

More specifically, we compared difference in prevalence between species in each species pair using the chi-square test. To test for differences in intensity, we performed a Bootstrap 2-sample t-test (with 2000 bootstrap replicates) between species in each species pair. We, therefore, performed ten tests, five tests to test for differences in prevalence between species in five species pairs and five tests to test for differences in mean intensities between species in the five species pairs. Both series of statistical tests were done in QP3.0 [24].

To explore any potential effects of geographical distribution on parasite prevalence or intensity, we simply inspected whether any significant differences between species in species pairs seemed to be predicted reliably by either the more or less widely distributed host species having either the higher or lower prevalence or intensity of Arrenurus spp. infection.

\section{DNA barcoding of Arrenurus}

To address whether host species of sibling species pairs might share putative mite species, and to have a preliminary account of host species range of those mite "species", DNA extractions from 62 larval mites was performed (from 70 larval water mites selected haphazardly, based principally on host species and site of host collection). This haphazard selection was as follows: five water mites were obtained from each host species from three different host individuals with mites coming from the thorax and/or abdomen (because thoracic and abdominal mites are often different species based on laboratory rearing of larval water mites through to adulthood (Bruce Smith, pers. comm.). All ten host species had thoracic mites. Four of ten species also had abdominal mites. In those latter species, both thoracic and abdominal water mites were collected, which is why sample size was initially 70 .

Total genomic DNA was extracted from whole specimens for 24 hours using a DNeasy Tissue kit (Qiagen Inc., Santa Clara, CA, USA). Following extraction, mites were removed from the extraction buffer, and genomic DNA was purified following the DNeasy Tissue kit protocol. PCR amplifications were performed following the protocol of Mlynarek et al. [17], amplification cycles were performed on an Eppendorf ep Gradient S Mastercycler (Eppendorf AG, Hamburg, Germany). Primer pairs Alt-ALF1 (5'-GCDTGRTCWGGRATAGTDGGAGCM AG-3') + Alt-ALR1 (5'- GACCCRGCYGGAGGDG GRG -3'), and LCO1490 + HCO2198 [26] were used to attempt to amplify a $608 \mathrm{bp}$ and $708 \mathrm{bp}$ fragment, respectively, of the $5^{\prime}$-end of COI of Arrenurus 
larvae and not their damselfly hosts. The thermocycler protocol for COI amplification was as follows: initial denaturation cycle at 94PC for $3 \mathrm{~min}$, followed by 45 cycles of $94 \mathrm{PC}$ for $45 \mathrm{~s}$, primer annealing at $45 \mathrm{PC}$ for $45 \mathrm{~s}$, 72PC for $1 \mathrm{~min}$, and a final extension at 72PC for $5 \mathrm{~min}$.

Amplified products and negative controls were visualized on $1 \%$ agarose electrophoresis gels, and purified using pre-cast E-Gel CloneWell 0.8\% SYBR Safe agarose gels (Invitrogen, Carlsbad, CA, USA) following Gibson et al. [27]. Sequencing reactions followed the protocol of Knee et al. [28], and sequencing was performed at the Agriculture \& Agri-Food Canada, Eastern Cereal and Oilseed Research Centre Core Sequencing Facility (Ottawa, ON, Canada).

Sequence chromatograms were edited and contiguous sequences were assembled using Sequencher v4.7 (Gene Codes Corp., Ann Arbor, MI, USA). COI sequences were aligned manually in Mesquite v2.74 [29] according to the translated amino acid sequence. Sequences have been submitted to GenBank (KF880845-KF880906). Homologous sequences from eight Arrenurus sp. individuals collected from Nehalennia gracilis and $N$. irene damselflies [21] were included in the COI alignment, and seven water mite species were selected from GenBank to serve as outgroups (AB530314, JX838402, JX836526, JX835088, JN018105, JN018109, AB530311).

Pairwise distances were calculated using neighbourjoining analysis with the uncorrected ("p") model in PAUP* v4.0b10 [30]. Phylogenetic analysis of the COI dataset was performed using Bayesian inference (BI) in MrBayes v3.1.2 $[31,32]$. The best-fit model of molecular evolution was determined to be GTR $+\mathrm{I}+\mathrm{G}$, using MrModeltest v2.3 [33]. Bayesian analysis was performed in MrBayes with a Markov Chain Monte Carlo (MCMC) method, two independent runs, with nucmodel $=4$ by $4, \mathrm{~N}_{\mathrm{st}}=6$, rates = invgamma, samplefreq $=1000$, four chains $=$ one cold and three heated, 10 million generations. In Mesquite, the remaining trees, excluding the burn-in (100), were used to generate a majority-rule consensus tree displaying the posterior probability supports for each node. Bayesian analysis was performed using the Cyberinfrastructure for Phylogenetic Research (CIPRES) portal [34]. In TNT v1.1 [35] node support was assessed using jackknife resampling with $36 \%$ of characters removed and 1000 replicates, using a heuristic search with tree bisectionreconnection (TBR) branch swapping and 1000 random addition sequence replicates.

\section{Statistical measures of mite richness and composition}

We used the Bray-Curtis dissimilarity index to determine whether water mite species richness and composition differed more between or within host species pairs in $\mathrm{R}$ using vegdist in the package VEGAN [36].

\section{Authors' contributions}

JJM MRF and WK co-wrote the manuscript. JJM and MRF conceived of the study and design. JJM collected the data. JJM and MRF performed the statistical analyses. WK performed the molecular work and analyses. All authors read and approved the final manuscript.

\section{Acknowledgments}

We thank A. Morrill, V. Putinsky and L. Nagel for help in the field and discussion of this project, C. Hassall for help with determining the geographic sizes of the species, and J. Skevington and S. Kelso for allowing us to use their facilities for the molecular work. This study was funded by an NSERC CGS awarded to JJM and an NSERC discovery grant awarded to MRF.

\section{Author details}

'Department of Biology, Carleton University, Nesbitt Building, 1125 Colonel By Drive, Ottawa, ON K1S 5B6, Canada. ${ }^{2}$ Canadian National Collection of Insects, Arachnids and Nematodes, Agriculture and Agri-Food Canada, 960 Carling Avenue, K.W. Neatby Building, Ottawa, ON K1A 0C6, Canada.

Received: 11 October 2013 Accepted: 16 December 2013

Published: 18 December 2013

\section{References}

1. Poulin R: Evolutionary Ecology of Parasites. Princeton university press; 2007.

2. Bordes F, Morand S, Krasnov BR, Poulin R: Parasite diversity and latitudinal gradients in terrestrial mammals. In The Biogeography of Host-Parasite Interactions. Edited by Morand S, Krasnov BR. New York: Oxford University press; 2010:89-98

3. Dritschilo W, Cornell H, Nafus D, O'Connor B: Insular biogeography: of mice and mites. Science 1975, 190:467-469.

4. Simková A, Morand S, Matejusová I, Jurajda P, Gelnar M: Local and regional influences on patterns of parasite species richness of central European fishes. Biodivers Conserv 2001, 10:511-525.

5. Krasnov BR, Stanko M, Miklisova D, Morand S: Habitat variation in species composition of flea assemblages on small mammals in central Europe. Ecol Res 2006, 21:460-469.

6. Kennedy CR, Bush AO: The relationship between pattern and scale in parasite communities: a stranger in a strange land. Parasitology 1994, 109:187-196.

7. Krasnov BR, Shenbrot GI, Medvedev SG, Vatshenok VS, Khokhlova IS: Host-habitat relations as an important determinant of spatial distribution on flea assemblages (Siphonaptera) on rodents in the Negev Desert. Parasitology 1997, 114:159-173.

8. Morand S, Krasnov BR: The Biogeography of Host-Parasite Interactions. New York: Oxford University Press; 2010

9. Tella JL, Blanco G, Manuela GF, Gajón Á, Donázar JA, Hiraldo F: Habitat, world geographic range, and embryonic development of hosts explain the prevalence of avian hematozoa at small spatial and phylogenetic scales. Proc Natl Acad Sci USA 1999, 96:1785-1789.

10. Poulin R, Morand S: Parasite Biodiversity. Washington DC: Smithsonian Books; 2004

11. Mlynarek JJ, Hassall C, Forbes MR: Higher gregarine parasitism often in sibling species of host damselflies with smaller geographical distributions. Ecol Entomol 2012, 37:419-425.

12. Gregory RD: Parasites and host geographic range as illustrated by waterfowl. Funct Ecol 1990, 4:645-654.

13. Price PW, Clancy KM: Patterns in number of helminth parasite species in freshwater fishes. J Parasitol 1983, 69:449-454.

14. Durrer S, Schmid-Hempel P: Parasites and the regional distribution of bumblebee species. Ecography 1995, 18:114-122.

15. Jaenike J, Perlman SJ: Ecology and evolution of host-parasite associations: Mycophagous Drosophila and their parasitic nematodes. Am Nat 2002, 160:\$23-\$39.

16. Ilvonen A, Ilvonen JJ, Kaunisto KM, Krams I, Suhonen J: Can infection by eugregarine parasites mediate species coexistence in Calopteryx damselflies? Ecol Entomol 2011, 36:582-587

17. Mlynarek JJ, Knee W, Forbes MR: Explaining susceptibility and resistance to a multi-host parasite. Evol Biol 2013. 10.1007/s11692-013-9251-6.

18. Forbes MR, Robb T: Testing hypotheses about parasite-mediated selection using odonate hosts. In Dragonflies and Damselflies: Model Organisms for 
Ecological and Evolutionary Research. Edited by Córdoba-Aguilar A. Oxford: Oxford University Press; 2008:175-188.

19. Nagel L, Mlynarek JJ, Forbes M: Immune response to nylon filaments in two damselfly species that differ in their resistance to ectoparasitic mites. Ecol entomol 2011, 36:736-743.

20. Grant PBC, Samways MJ: Ectoparasitic mites infest common and widespread but not rare and red-listed dragonfly species. Odonatologica 2007, 36:255-262.

21. Smith IM, Cook DR, Smith BP: Water mites (Hydrachnidiae) and other arachnids. In Ecology and Classification of North American Freshwater Invertebrates. 3rd edition. Edited by Thorp JH, Covich AP. London: Academic Press; 2010:485-587.

22. Cognato Al: Standard percent DNA sequence difference for insects does not predict species boundaries. J Econ Entomol 2006, 99:1037-1045.

23. May ML: Phylogeny and taxonomy of the damselfly genus Enallagma and related taxa (Odonata: Zygoptera: Coenagrionidae). Syst Entomol 2002, 27:387-408.

24. Rózsa L, Reiczigel J, Majoros G: Quantifying parasites in samples of hosts. J Parasitol 2000, 86:228-232.

25. Zar JH: Biostatistical analysis. New Jersey: Prentice-Hall, Englewood Cliffs; 1984:718.

26. Folmer OM, Black W, Hoeh R, Lutz R, Vrijenhoek R: DNA primers for amplification of mitochondrial cytochrome $c$ oxidase subunit I from diverse metazoan invertebrates. Mol Mar Biol Biotech 1994, 3:294-299.

27. Gibson JF, Kelso S, Skevington JH: Band-cutting no more: a method for the isolation and purification of target PCR bands from multiplex PCR products using new technology. Mol Phylogenet Evol 2010, 56:1126-1128.

28. Knee W, Beaulieu F, Skevington JH, Kelso S, Forbes MR: Cryptic species of mites (Uropodoidea: Uroobovella spp.) associated with burying beetles (Silphidae: Nicrophorus): The collapse of a host generalist revealed by molecular and morphological analyses. Mol Phylogenet Evol 2012, 65:276-286

29. Maddison WP, Maddison DR: Mesquite: a modular system for evolutionary analysis v2.74. ; 2010. http://mesquiteproject.org.

30. Swofford DL: PAUP*. Phylogenetic analysis using parsimony (*and other methods). Version 4.0b10. Sunderland, Massachusetts: Sinauer Associates; 2003.

31. Huelsenbeck JP, Ronquist F: MRBAYES: Bayesian inference of phylogenetic trees. Bioinformatics 2001, 17:754-755.

32. Ronquist F, Huelsenbeck JP: MRBAYES 3: Bayesian phylogenetic inference under mixed models. Bioinformatics 2003, 19:1572-1574

33. Nylander JAA: MrModeltest v2. Program distributed by the author. Uppsala: Evolutionary Biology Centre, Uppsala University; 2004.

34. Miller MA, Pfeiffer W, Schwartz T: Creating the CIPRES science gateway for inference of large phylogenetic trees. In Proceedings of the Gateway Computing Environments Workshop (GCE). New Orleans, Louisiana: IEEE; 2010:1-8.

35. Goloboff PA, Farris JS, Nixon KC: TNT, a free program for phylogenetic analysis. Cladistics 2008, 24:774-786.

36. Jari Oksanen J, Blanchet FG, Kindt R, Legendre P, Minchin PR, O'Hara RB, Simpson GL, Solymos P, Stevens MHH, Wagner H: Vegan: Community Ecology Package. R package version 2.0-7. 2013. http://CRAN.R-project.org/ package= vegan

\section{doi:10.1186/1472-6785-13-50}

Cite this article as: Mlynarek et al: Relative geographic range of sibling species of host damselflies does not reliably predict differential parasitism by water mites. BMC Ecology 2013 13:50.

\section{Submit your next manuscript to BioMed Central and take full advantage of:}

- Convenient online submission

- Thorough peer review

- No space constraints or color figure charges

- Immediate publication on acceptance

- Inclusion in PubMed, CAS, Scopus and Google Scholar

- Research which is freely available for redistribution

Submit your manuscript at www.biomedcentral.com/submit 